\title{
The Effect of Delthamethrin Treated Net on Tsetse and other Insects in Shara Kebeles, Gamo Gofa Zone, Snnprs
}

\author{
Firew Lejebo $^{1 *}$, Daniel Dumale ${ }^{2}$, Befekadu Urga ${ }^{2}$, Esayas Balcha ${ }^{1}$ \\ National institute for control and eradication of tsetse and trypanosmiasis, Arba Minch Station, Arba Minch \\ and Jig-jiga university, college of veterinary medicine, Jig-jiga, Ethiopia
}

\begin{abstract}
*Corresponding Author: Firew Lejebo, National institute for control and eradication of tsetse and trypanosmiasis, Arba Minch Station, Arba Minch and Jig-jiga university, college of veterinary medicine, Jig-jiga, Ethiopia
\end{abstract}

\begin{abstract}
There are different flies including tsetse flies, biting flies and other nuisance flies that disturb animal by either biting or landing on their body while attempting to feed on their blood or body secretions. The flies may play a disease transmission role or simply cause nuisance and restlessness to animals resulting loss of body condition and production. Various efforts have been made by the Southern Tsetse Eradication Project (STEP) and many places in Ethiopia to control the flies and great advances have been made. The experimental study was designed to measure whether Deltamethrin-treated screen to reduce fly densities within and around a pen fenced with the treated screen and assess the effective persistence of the insecticide on the screen. Two identical cattle pens of $4 m \times 4 m$ size were constructed for the study at Shara and two-five oxen were introduced in to each pen. One pen was fenced with insecticide treated screen as treatment group while the second pen was left unfenced for a control group. Defensive movements of different animal body (skin ripples, tail switch, leg kicks, head \& ear movement) were monitored at 10 days interval for 5 months. The fly density around the pen was monthly monitored using 15 NGU traps were deployed for 5 months 5 meters away from the cattle pens and blood sample of all animals was examined for trypanosomosis and Packed Cell Volume (PCV). The result of the study showed that the defensive movements of experimental animals were higher in the first $10^{\text {th }}$ day of first monitoring cycle and drastically declined until close to zero at $3^{\text {rd }}$ monitoring cycle which continued the same up to the $5^{\text {th }}$ which is the last monitoring of this study. Generally the no. of all flies (insects) in control group was higher in control group than experimental group $(p=0.000)$. The parasitological results of the study has shown negative result on experimental group during the full monitoring cycle but was positive results in control group during monitoring cycles two. Animals kept under insecticide sprayed net had significantly higher $(p=0.000)$ PCV than those kept without net on all subsequent occasions. Milk yield of animals kept under insecticide sprayed net (treatment) were not significantly different from those kept without net (controls) on the the first 4 follow up observations due to feed management problem of farmers. However, treatment group animals had significantly higher $(p=0.033)$ milk yield than controls on the $5^{\text {th }}$ follow up observation. This insecticide treated net will help the farmers in getting revenue and relief from flies. In order to get a planned result from the livestock sector and so as to sustain result achieved so far it has to be done in different geographic areas and Seasonal study to support the poor community.
\end{abstract}

Keywords: Acetone, Control, Defensive movement, Experimental, Insecticide impregnated net, Pen and Trap.

\section{INTRODUCTION}

Trypanosomosis is caused by several species of blood and tissue dwelling protozoan parasites encountered throughout the southwest of Ethiopia (ABEBE, and JOBRE, 1996). The most important trypanosome species affecting livestock in Ethiopia are Trypanosoma congolense, T. Vivax and T. Brucei in cattle, sheep and goats. evansiin camels, and T. equiperdumin horses (DAGNACHEW, and SHAFO,1981, LANGRIDGE, 1976, TAKELE, and ABEBE, 1988).Trypanosomosis in cattle, locally referred to as Gendi, is a serious constraint to live stock production in areas of the southwest of Ethiopia at altitudes lesser than $1700 \mathrm{~m}$ above sea level (LANGRIDGE, 1976). Animals bitten by tsetse flies develop fever, anemia, loses weight, and progressively become weak and unproductive. Ethiopia stands $1^{\text {st }}$ first in Africa and $10^{\text {th }}$ in the world in live stock population. The domestic animal population of the country is estimated to be 47.5 million cattle, 26.1 million sheep, 21.7 million goat, 1 million camel, 39.6 million chickens, 1.8 million horses, 0.4 million mules and 5.6 million donkeys 
(CSA, 2013). Although huge number of live stock population particularly cattle's due to tsetse transmitted trypanosomiasis the full utilization of products was hindered. One of the most economically important vectors born disease is trypanosomiasis transmitted by the Glossina species. Tsetse flies are responsible for the transmission of the protozoan parasites of the Genus Trypanosoma, the pathogenic agents of sleeping sickness in humans and nagana in cattle (Hu and Askoy, 2006). Tsetse flies are confined only to the afro tropical regions of Africa, where they occupy an area over 7 million $\mathrm{km}^{2}$. Out of the thirty one species and subspecies described in Africa (Goodings and Krafsur, 2005).The genus Glossina consists of three distinct subgenera, Morsitans (Glossina), Palpalis (Nemorhina) and Fusca (Austenina). These subgenera were differentiated on anatomical features and on their restriction to a relatively specific habitat Leak (1999) quoted in Goodings and Krafsur (2005), thus the Morsitans group were classed as savannah-inhabiting species, Palpalis group as riverine or lacustrine species and Fusca group as forest-inhabiting species (Leak et al., 2008). Their distribution and abundance being determined by the vegetation type along river banks (Bouyer et al., 2005). Tsetse and trypanosomiasis lies at the heart of Africa's struggle against poverty affecting 37 countries in sub-Saharan Africa where the disease is endemic (PAAT, 2008). It is recognized as a neglected disease, principally because it is rural and its impact on the socio-economic development is devastating (Oluwafemi, 2009).Tsetse flies infestation in most National Parks and Game Reserves poses a major health risk to tourist coming in to tropical Africa (Conway-Klaassenet al, 2002, Jelinek et al., 2002, Sabbah et al., 1997) quoted in (Abenga and Lawal, 2005) as well as to rural communities and livestock. Now a day, due to shortage of grazing land farmers are forced to use other alternatives methods. In order to full fill this livestock protective fence is the ultimate option increasing a awareness of the peoples regarding livestock particularly cattle's as a source of income and peoples in many parts of the country started fattening and dairy farming. This activities definitely need livestock protective fence for the reason that the animals are confined or limited to specific area for indoor feeding. During this time 30 farmers with a net being installed and 5 farmers from Shara kebele were used for the experiment and control groups respectively. This time fly population, defensive movement, and parasitological examinations, mean PCV value average milk production and weight gain, starting from October, 2014 were considered.

The net enable the farmers to increase milk and meat production, improve the living condition of farmers, and increase the economy of the country, and ultimately getting the hard currency that the government is planning to get from the live stock sector. Once the technology was proved to be effective it will be transferred in to the communities in nearby and to the countries at large. Breeding animals frequently abort or may become infertile. Severely affected animals die of anaemia, congestive heart failure or inter current bacterial infections that frequently take advantage of the weakened immune system. At past, a principal approach to control trypanosomosis in Ethiopia was prevention or treatment of animals using trypanocidal drugs. This approach however, has many drawbacks such as the high cost of drugs and insecticides, possibilities of undesirable environmental pollution by insecticides, the increasing development of resistance in the parasites to the existing drugs and the lack of new drugs to replace them. Because of the potential threat, drug resistance in trypanosomes poses to livestock production. This was not effective and as option another way was aimed that was control or elimination of tsetse flies. Therefore, the study was aimed at creating a highly attractive area in the pen by placing animals for specific study period to measure whether the Deltamethrin-treated Screen (net) reduces fly densities within and around the pen and longevity of effective persistence of the insecticide on the treated. The aim of this study was therefore to assess the degree of resistance of $T$. Congolense in the southwest of Ethiopia, where trypanocidal drugs were routinely used. (Alemu T, et al, 2007, Awoke, K, 2000). Apart from disease transmission tsetse flies, tabanids and other biting flies also cause nuisance and restlessness to animals if not well protected using different control techniques. (Bauer B., 2011). Various efforts have been made over the last decades and great advances have been made in fighting tsetse and trypanosomosis with considerable reduction of the problem. The techniques used for tsetse flies control programs in different parts of Ethiopia have also made great contribution in reducing challenges posed by different species of biting and nuisance flies (Alemu T, et al, 2007, Bauer B,. et al 1992, Bauer B,. et al 1995). Maia MF, 2010). However, since the efforts were of short period, scattered and uncoordinated, Trypanosomosis transmission continued to persist in different parts of the country contributing to food insecurity. Tsetse flies suppression using area wide integrated pest management (AW-IPM) approach was implemented in different parts of the country including the areas identified for the experiment at Arba Minch to eliminate the problem (Alemu T, et al., 2007,.Awoke, K, 2000.,Bauer B,.1992). However, 
tsetse and other biting flies that comes from Nech Sar National Park rests on different animals grazing around the park and cause nuisance to animals in the vicinity affecting their production and productivity. In addition, several similar reports have been received from different places of the country where tsetse flies have been eliminated using different control techniques (Alemu T, et al., 2007). This could be due to the newly emerging flies in the area or reinvasion from the surrounding areas. Fencing deltamethrin-treated Screen (Zero Fly® livestock) around cattle pen was proposed as an option to reduce challenges from tsetse and other biting flies. Besides killing the flies, the technology was designed to protect individual animals from fly attack (Bauer B, et al 2011, Maia MF, 2010). The technique would eliminate tsetse flies, biting flies and other nuisance flies and create sustainable condition for livestock rearing under indoor feeding or Zero grazing system to be considered as an alternative and cost effective vector control technique in the rural areas(Bauer $\mathrm{B},$. et al 2006).

\subsection{The Objectives of the Study}

- Protection of live stock from disease trypanosomiasis and other vector born disease.

- Protection of cattle's from biting flies ather flies to increase production and productivity

\section{Materials AND Methods}

\subsection{Study Area}

The study was conducted in Arba Minch zuria woreda Shara kebele of Gamo Gofa Zone in the Southern Nation Nationalities and Peoples Region (SNNPR) located at about $515 \mathrm{~km}$ from Addis Abeba, the capital city of Ethiopia. The area receives an annual rain fall of $800-1200 \mathrm{~mm}$ and average annual temperature of $26.330 \mathrm{c}$. The altitude of the district ranges from 1001 to 2500 masl. The area receives an annual rain fall of $800-1600 \mathrm{~mm}$ and average annual temperature of $27.50 \mathrm{c}$. The altitude of the district ranges from 1100 to 2900 masl (AzWDA, 2007).

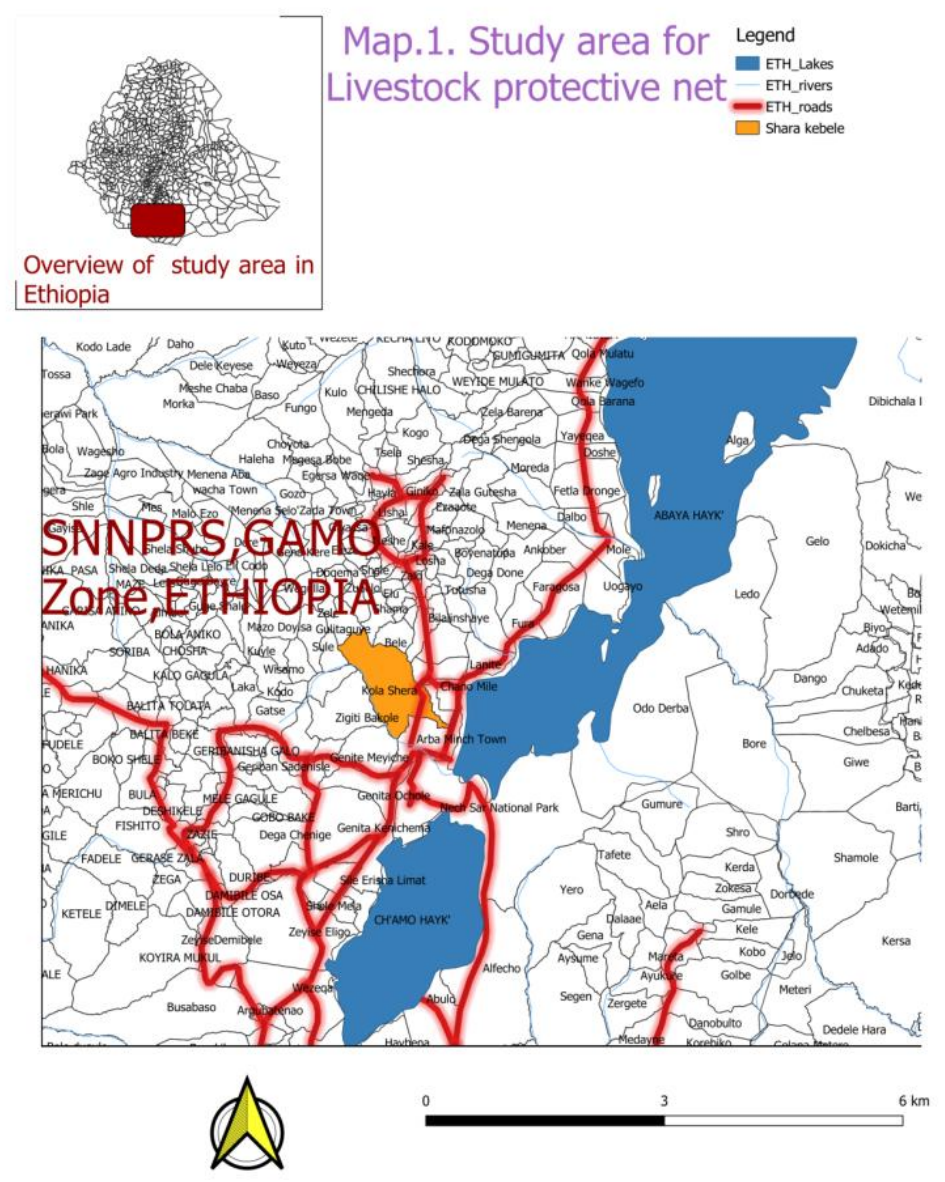

WGS 84 UTM zone 37,Arba Minch,Ethiopia,July,2019.

Figure1. Study area 


\subsection{Study Population}

During this time experimental study was made on 30 selected farmers undertaken starting from October, 2014 to May, 2015. The number of animals kept in the pen varies within the farmers based on their capacity to use zero grazing, and on the number of animal's individual own. On average one farmer held two-ten animals for the experiment for experimental as well as control groups. The farmers were selected based on their way of handling and effectively using them for production. On the other hand, five farmers were selected as non-treated group for the study. Two-five animals were handled by each farmer for the control purpose. (AZWRA, 2007).

\subsection{Study Design}

An experimental study was conducted to assess and check the effect of insecticide treated net on tsetse flies and other insects. During this experiment PCV values, defensive movements, milk yield and weight gain was measured for both experimental and control groups were used.

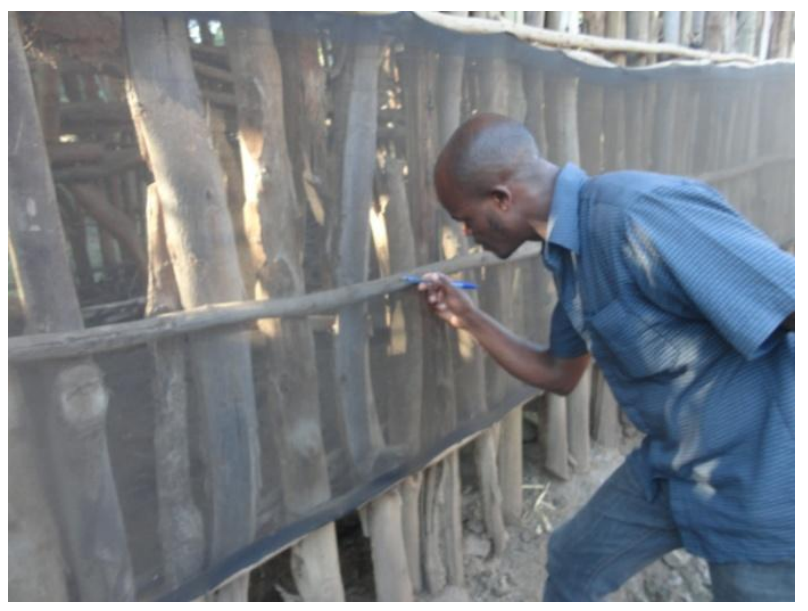

Figure. Experimental group

\subsection{Sampling Method}

The farmers were purposively selected and considered for the experiment. The collection of data was primarily based on the baseline data from each of the 30 experimental and 5 control groups. The data collection was made for entomological, parasitological, PCV, defensive movements and milk production throughout the study period.

\subsection{Study Methodology}

\subsubsection{Field Trials and Data Collection}

The pen was constructed $4 \mathrm{mx} 4 \mathrm{~m}$ size, the net with height of 1 meter and $10 \mathrm{~cm}$ above the ground. For the treated group 30 farmers were selected and 30 pens were contracted for each farmer. The net was incorporated with ultraviolet (UV) protection to increase its longevity. Based on the installation guideline obtained from the vestegard frandson company, two identical cattle pens of $4 \mathrm{~m} \times 4 \mathrm{~m}$ size with different number of animals holding capacities were constructed using wooden plank and the roof was made of corrugated iron sheet. The floor of the pen was not made of concrete but levelled soil. The first pens were allocated for treated group and the second pen was allocated for control group. Two oxen of the same age and body condition were placed in each pen and maintained under the same feeding and management condition. The oxen used for the study were local Zebu breeds. During the study history of the cattle were taken to know the origin of the animals to make sure that they didn't have received insecticide treatment during the last 6 months which could have some effect on the result of the experiment. All animals in both groups were given different names for identification depending on their colours. The pen allocated for treated groups were stretched with 1 $\mathrm{m}$-high treated screen. Defensive movements were closely monitored for 5 cycles and with this skin ripples, tail switch, leg kicks, head and ear movement in response to the flies contact were recorded. The defensive movement of each part of the body was observed for 5 minutes at every monitoring cycle and the number of movements recorded accordingly and the summation of the number of defensive movement of different body parts was recorded. 


\subsubsection{NGU Trap for Entomological Survey}

Entomological monitoring was conducted to know the presence and densities of tsetse and other nuisance flies using $15 \mathrm{NG} 2 \mathrm{G}$ traps 10 for treated group and 5 for control group were baited with phenol and deployed at a distance of $5 \mathrm{~m}$ away from treated and control pens. The attractant acetone was used by putting it under the trap stretched. The flies caught during the study were identified by and recorded. During this time 15 traps were deployed in shara kebele and flies were collected after $72 \mathrm{hrs}$. The fly identification was based on their morphology of wing shape and their body size. The data collection was monthly. The pen allocated for the control group was left unfenced. The data obtained during the experiment was stored in the micro-soft excel spread sheet and the defensive movements, fly density, trypanosomosis prevalence, PCV, and persistence of the activity of the insecticide were analysed. The difference between experimental and control groups were compared to understand the effect of the deltamethrin-treated screen/net on the density of tsetse flies, tabanids and other nuisance flies around the pen(Machado A, 1954).

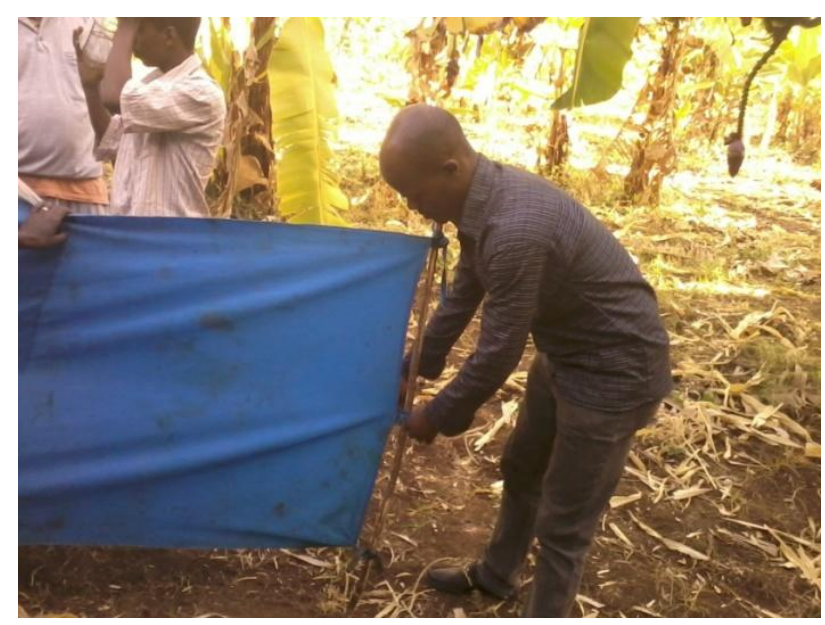

Figure2. $N G U$ trap

\subsubsection{Parasitological Examination}

During this time animals examined for the presence of parasite and difference in PCV value. Monitoring activity was done once in a month. Each of the animals from thirty selected farmers house for experimental group and each of the animals from five farmers for control groups were considered for the study. Blood samples were collected via capillary with anti coagulant from the ear vein of the cattle. The Buffy coat method (MURRAY M et al. 1977.) was used to assess the presence trypanosomosis causing parasite in the blood of each examined animals.

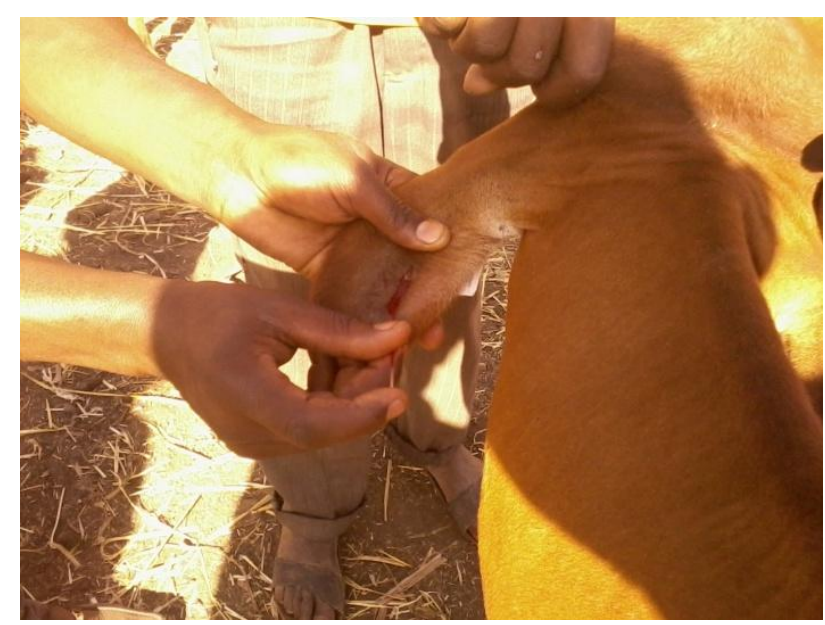

\subsubsection{Milk Yield}

Milk yield data was collected for the animals on monthly basis. Before the commencement of the experiment initial data for the milk production was collected by questionnaire prepared for each of the house hold which enables to compare the production increment in both treated and control groups. 
The production data regarding weight gain was collected in a qualitative form even though affected by frequent selling, and absence of equipment to exactly measure the weight gain. The weight gain was estimated by body score condition of the treated, and control group of animals, however not written in detail as another parameters (factors) like PCV, defensive movement, parasitology and fly infestation were considered.

\subsubsection{Defensive Movement Study}

The defensive movement produced by animals were observed for five minutes in each of the treated and control groups. Based on that the movements were observed in each of the four different parts of the body of animals. The movements on the parts of body of animals observed were head and ear movement, tail switching, skin ripples and leg kick. The expectation of the defensive movement differ in experimental and control group as decreased from time to time in experimental group and increased in control group.

\subsubsection{Packed Cell Volume Study (PCV) Study}

Haemoparasites affects the volume of cells by haemolysis which results in anaemia. Therefore, PCV will help to analyze the concentration of blood cells in the animals' body (Murray et al., 1983).

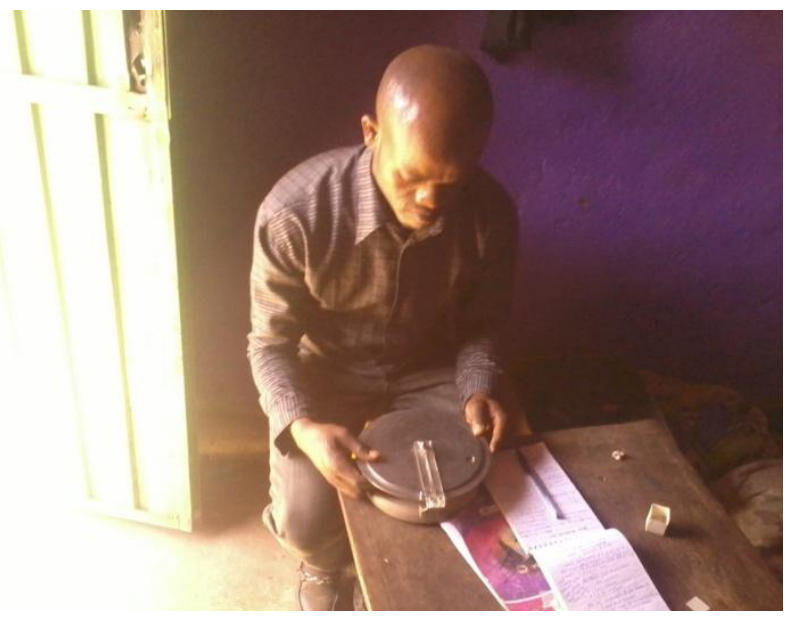

Figure3. Haematocrit reader

\section{DATa MANAGEMENT AND ANALYSIS}

Microsoft Excel was used to store all the data and Stata version 14.2 were used to analyze the data. Summary Statistical tests like mean and standard errors were used to compares PCV, Milk yield and Defensive movements. On the other hand, ANOVA were used to analyse Parasitological data on trypanosome prevalence, tsetse, biting and others flies to evaluate the association with different variables like Milk yield, defensive movement and PCV.

\section{Results}

\subsection{Defensive Movement Result}

Defensive movement of animals against insect infestation was recorded for 4 control group animals and 30 treatment group animals. Overall, frequency of defensive moves ranged from a minimum of 0 to a maximum of 25. Frequency of defensive moves was comparable between treatment and control group animals over the first two follow up observations. Meanwhile, animals kept under insecticide sprayed net fitted housing had significantly lower frequency of defensive moves on $3^{\text {rd }}(p=0.006), 4^{\text {th }}$ $(\mathrm{p}=0.000)$ and $5^{\text {th }}(\mathrm{p}=0.000)$ rounds of follow up observation. (Table 1)

Table1.

\begin{tabular}{|c|c|c|c|c|c|}
\hline \multirow{2}{*}{ Group } & \multicolumn{5}{|c|}{ Defensive Moves } \\
\cline { 2 - 6 } & Month 1 & Month 2 & Month 3 & Month 4 & Month 5 \\
\hline Control & $9.50 \pm 0.500$ & $10 \pm 0.50$ & $10.75 \pm 0.479$ & $170.25 \pm .479$ & $17.75 \pm .479$ \\
\hline Treatment & $12.27 \pm$ & $9.17 \pm$ & $5.43 \pm$ & $3.30 \pm$ & $2.80 \pm$ \\
\hline Total & Total & $11.94 \pm .532$ & $9.32 \pm .497$ & $6.06 \pm .646$ & $4.94 \pm .827$ \\
\hline
\end{tabular}


The Effect of Delthamethrin Treated Net on Tsetse and other Insects in Shara Kebeles, Gamo Gofa Zone, Snnprs

\subsection{Entomological Result}

Entomological survey was conducted on 5 control and 10 treatment group. Over all a total no. of 13 tsetse flies, 122 biting flies and 326 other insects were captured using traps as shown bellow in table1.The no. of tsetse flies $(\mathrm{p}=0.006)$, biting flies $(\mathrm{p}=0.000)$ and other insect $(\mathrm{p}=0.000)$ in control group was higher than experimental group in follow up observation. Generally the no. of all flies (insects) in control group was higher in control group than experimental group $(\mathrm{p}=0.000)$ (Tables 1 and 2)

Table2. Comparison of insects load on follow up observation

\begin{tabular}{|l|l|l|l|l|}
\hline Groups & Tsetse fly total & Biting total & Others total & OVERALL(mixed) \\
\hline Contrrol & $2.20 \pm .800$ & $15.00 \pm 1.483$ & $29.40 \pm 2.028$ & $64.40 \pm 6.675$ \\
\hline Treated & $0.20 \pm .200^{*}$ & $3.10 \pm .875$ & $9.70 \pm 2.028$ & $26.10 \pm 4.291$ \\
\hline Total & $0.87 \pm .376$ & $7.07 \pm .376$ & $16.27 \pm 3.020$ & $38.87 \pm 5.951$ \\
\hline
\end{tabular}

Table3. Frequency of insects trapped on follow up observation

\begin{tabular}{|c|c|c|c|c|}
\hline Insects & Group & Initiation of study & Follow up observation & Total \\
\hline \multirow[t]{3}{*}{ Tsetse fly } & Control & 1 & 10 & \\
\hline & Treatment & 0 & 2 & \\
\hline & Total & 1 & 12 & \\
\hline \multirow[t]{3}{*}{ Biting flies } & Control & 0 & 31 & \\
\hline & Treatment & 16 & 75 & \\
\hline & Total & 16 & 106 & \\
\hline \multirow[t]{3}{*}{ Others } & Control & 0 & 147 & \\
\hline & Treatment & 82 & 97 & \\
\hline & Total & 82 & 244 & \\
\hline \multirow[t]{3}{*}{ All insects } & Control & 0 & 322 & \\
\hline & Treatment & 82 & 261 & \\
\hline & Total & 82 & 583 & \\
\hline
\end{tabular}

\begin{tabular}{|c|c|c|c|c|c|c|c|}
\hline Insect & Months & Mean (SE) & $95 \%$ CI - LB & $95 \%$ CI - UB & Control & Treatment & Sig \\
\hline \multirow{5}{*}{ Total } & $1^{\mathrm{st}}$ & $6.7(2.0)$ & 2.39 & 11.08 & $0.6(0.4)$ & $9.8(2.5)$ & $\mathrm{p}=0.007$ \\
\hline & $2^{\text {nd }}$ & $4.8(1.4)$ & 1.86 & 7.74 & $8.6(3.0)$ & $2.9(1.1)$ & $\mathrm{p}=0.048$ \\
\hline & $3^{\text {rd }}$ & $2.5(0.75)$ & .91 & 4.15 & $3.2(1.8)$ & $2.2(0.7)$ & $\mathrm{p}=0.801$ \\
\hline & $4^{\text {th }}$ & $9.3(1.9)$ & 5.19 & 13.34 & $17.6(1.8)$ & $5.1(1.4)$ & $\mathrm{p}=0.002$ \\
\hline & $5^{\text {th }}$ & $7.6(2.1)$ & 3.17 & 12.03 & $17.2(1.8)$ & $2.8(1.25)$ & $\mathrm{p}=0.002$ \\
\hline \multirow{5}{*}{$\begin{array}{l}\text { Tse-tse } \\
\text { fly }\end{array}$} & $1^{\text {st }}$ & $0.2(0.15)$ & -0.11 & 0.51 & $0.6(0.4)$ & 0 & $\mathrm{p}=0.038$ \\
\hline & $2^{\text {nd }}$ & $0.4(0.2)$ & 0.00 & 0.81 & $1(0.45)$ & $0.1(0.1)$ & $\mathrm{p}=0.032$ \\
\hline & $3^{\text {rd }}$ & $0.07(0.07)$ & -0.08 & 0.21 & 0 & $0.1(0.1)$ & $\mathrm{p}=0.480$ \\
\hline & $4^{\text {th }}$ & $0.2(0.2)$ & -0.23 & 0.63 & $0.6(0.6)$ & 0 & $\mathrm{p}=0.157$ \\
\hline & $5^{\text {th }}$ & $0.2(0.15)$ & -0.11 & 0.51 & $0.6(0.4)$ & 0 & $\mathrm{p}=0.038$ \\
\hline \multirow{5}{*}{$\begin{array}{l}\text { Biting } \\
\text { fly }\end{array}$} & $1^{\mathrm{st}}$ & $1.07(0.45)$ & 0.10 & 2.04 & 0 & $1.6(0.6)$ & $\mathrm{p}=0.038$ \\
\hline & $2^{\text {nd }}$ & $1.5(0.55)$ & 0.29 & 2.65 & $3.6(1.1)$ & $0.4(0.2)$ & $\mathrm{p}=0.002$ \\
\hline & $3^{\text {rd }}$ & $0.5(0.2)$ & 0.07 & 1.00 & $1(0.45)$ & $0.3(0.2)$ & $\mathrm{p}=0.123$ \\
\hline & $4^{\text {th }}$ & $2.07(0.5)$ & 0.91 & 3.22 & $3.4(1.1)$ & $1.4(0.5)$ & $\mathrm{p}=0.079$ \\
\hline & $5^{\text {th }}$ & $3.0(0.9)$ & 1.05 & 4.95 & $7(1.3)$ & $1(0.5)$ & $\mathrm{p}=0.003$ \\
\hline \multirow{5}{*}{$\begin{array}{l}\text { Other } \\
\text { insects }\end{array}$} & $1^{\text {st }}$ & $5.5(1.7)$ & 1.79 & 9.15 & 0 & $8.2(2.1)$ & $\mathrm{p}=0.002$ \\
\hline & $2^{\text {nd }}$ & $2.9(0.9)$ & 1.07 & 4.80 & $4(1.9)$ & $2.4(0.9)$ & $\mathrm{p}=0.616$ \\
\hline & $3^{\text {rd }}$ & $2.4(0.8)$ & 0.71 & 4.12 & $2.2(1.7)$ & $2.6(0.7)$ & $\mathrm{p}=0.202$ \\
\hline & $4^{\text {th }}$ & $7.0(1.4)$ & 3.92 & 10.08 & $13.6(1.2)$ & $3.7(0.9)$ & $\mathrm{p}=0.002$ \\
\hline & $5^{\text {th }}$ & $4.4(1.2)$ & 1.85 & 6.95 & $9.6(0.5)$ & $1.8(1.0)$ & $\mathrm{p}=0.002$ \\
\hline
\end{tabular}


The Effect of Delthamethrin Treated Net on Tsetse and other Insects in Shara Kebeles, Gamo Gofa Zone, Snnprs

\subsection{Parasitological Results}

The parasitological results of the study has shown negative result on experimental group during the full monitoring cycle, Meanwhile, there was positive results in control group during monitoring cycles two and cycle four involving $T$. congolence and $T$. vivax, respectively.

\subsection{Packed Cell Volume (PCV) Changes}

PCV values for control and treatment groups were comparable at start of the study. However, animals kept under insecticide sprayed net had significantly higher $(\mathrm{p}=0.000)$ PCV than those kept without net on all subsequent occasions. This result shows that the result and the aim of the study has gone proportionally. (Table 4)

Table4. Comparison of PCV changes

\begin{tabular}{|c|c|c|c|c|c|}
\hline \multirow{2}{*}{ Group } & \multicolumn{5}{|c|}{ PCV } \\
\cline { 2 - 6 } & PCV1 & PCV2 & PCV3 & PC V4 & PCV5 \\
\hline Control & $15.90 \pm 1.542$ & $15.67 \pm 1.460$ & $14.60 \pm 1.055$ & $16.33 \pm 1.436$ & $16.53 \pm 1.298$ \\
\hline Experimental & $18.49 \pm 1.058$ & $28.05 \pm 0.753$ & $27.90 \pm 0.980$ & $27.85 \pm 0.712$ & $24.80 \pm 0.867$ \\
\hline Total & $\mathbf{1 7 . 7 8} \pm \mathbf{0 . 8 8 3}$ & $\mathbf{2 4 . 6 7} \pm \mathbf{0 . 8 8 3}$ & $\mathbf{2 4 . 2 7} \pm \mathbf{1 . 1 1 1}$ & $\mathbf{2 4 . 7 1} \pm \mathbf{0 . 9 4 8}$ & $\mathbf{2 2 . 5 5} \pm \mathbf{0 . 8 7 5}$ \\
\hline
\end{tabular}

\subsection{Milk Yield Result}

Milk yield of study animals ranged from 1 to $6 \mathrm{~L}$ per day. Milk yield of animals kept under insecticide sprayed net (treatment) were not significantly different from those kept without net (controls) on the the first 4 follow up observations due to feed management problem of farmers. However, treatment group animals had significantly higher $(\mathrm{p}=0.033)$ milk yield than controls on the $5^{\text {th }}$ follow up observation (Table 5).

Table5. Milk yield comparison

\begin{tabular}{|l|l|l|l|l|l|}
\hline \multirow{2}{*}{ Group } & \multicolumn{5}{|c|}{ Milk } \\
\cline { 2 - 6 } & Month 1 & Month 2 & Month 3 & Month 4 & Month 5 \\
\hline Control & $1.875 \pm .2394$ & $1.500 \pm .2887$ & $1.125 \pm .1250$ & $1.250 \pm .2500$ & $1.000 \pm .0000$ \\
\hline treatment & $2.087 \pm .1769$ & $2.386 \pm .2371$ & $1.524 \pm .2140$ & $2.214 \pm .2058$ & $2.357 \pm .2213$ \\
\hline Total & $2.056 \pm .1541$ & $2.250 \pm .2135$ & $1.460 \pm .1824$ & $2.130 \pm .1969$ & $2.187 \pm .2145$ \\
\hline
\end{tabular}

Table5. Insect monitoring for study period

\begin{tabular}{|c|c|c|c|c|}
\hline Insects & Months & Negative & Positive & Sig. (2 Sided) \\
\hline \multirow{5}{*}{$\begin{array}{l}\text { Tse-tse } \\
\text { flies }\end{array}$} & $1^{\text {st }}$ & $0.15(0.15)$ & $0.5(0.5)$ & $p=0.437$ \\
\hline & $2^{\text {nd }}$ & $0.3(0.175)$ & $1(1)$ & $p=0.229$ \\
\hline & $3^{\text {rd }}$ & $0.08(0.08)$ & 0 & $p=0.710$ \\
\hline & $4^{\text {th }}$ & $0.2(0.2)$ & 0 & $p=0.710$ \\
\hline & $5^{\text {th }}$ & $0.15(0.15)$ & $0.5(0.5)$ & $p=0.437$ \\
\hline \multirow{5}{*}{$\begin{array}{c}\text { Biting } \\
\text { flies }\end{array}$} & $1^{\text {st }}$ & $1.2(0.5)$ & 0 & $p=0.374$ \\
\hline & $2^{\text {nd }}$ & $1.2(0.6)$ & $3(0)$ & $p=0.291$ \\
\hline & $3^{\text {rd }}$ & $0.5(0.2)$ & $1(1)$ & $\mathrm{p}=0.415$ \\
\hline & $4^{\text {th }}$ & $1.8(0.5)$ & $4(2)$ & $p=0.167$ \\
\hline & $5^{\text {th }}$ & $2.5(0.9)$ & $6(3)$ & $p=0.207$ \\
\hline \multirow{5}{*}{$\begin{array}{l}\text { Other } \\
\text { insects }\end{array}$} & $1^{\mathrm{st}}$ & $6.3(1.9)$ & 0 & $\mathrm{p}=0.224$ \\
\hline & $2^{\text {nd }}$ & $3.4(0.9)$ & 0 & $p=0.196$ \\
\hline & $3^{\text {rd }}$ & $2.8(0.9)$ & $0.5(0.5)$ & $p=0.288$ \\
\hline & $4^{\text {th }}$ & $5.9(1.4)$ & $14(1)$ & $\mathrm{p}=0.052$ \\
\hline & $5^{\text {th }}$ & $3.7(1.3)$ & $9.0(1)$ & $\mathrm{p}=0.018$ \\
\hline \multirow{5}{*}{ Total insects } & $1^{\mathrm{st}}$ & $7.7(2.2)$ & $0.5(0.5)$ & $\mathrm{p}=0.241$ \\
\hline & $2^{\text {nd }}$ & $4.9(1.6)$ & $4(1)$ & $p=0.828$ \\
\hline & $3^{\text {rd }}$ & $2.7(0.85)$ & $1.5(1.5)$ & $p=0.610$ \\
\hline & $4^{\text {th }}$ & $7.9(1.9)$ & $18(3.0)$ & $p=0.069$ \\
\hline & $5^{\text {th }}$ & $6.4(2.2)$ & $15.5(3.5)$ & $p=0.139$ \\
\hline
\end{tabular}

\section{DISCUSSION}

Flies affect productivity and production of animals through disease transmission or nuisance (STEP, 2014). Diseases increase morbidity and mortality of cattle whereas nuisance leads to animal 
disturbance and reduction in feed-intake (Sachs and Malaney, 2002). During the present study defensive movement produced by the animals was reduced during the period as shown in table 1 . And the entomological study, the number of fly population was reduced during the period as shown in table 2a-2f. This finding has similar result with the research done by (Mahama et al., 2004a; Mahama et al., 2004b) who indicated that the animals within the pen protected with a treated net had significantly fewer insects counted on their body regions and performed the least defensive movements. In our present study in the control groups the number of flies' population was linearly increased as it was shown in table 2. The animals in this pen appeared calmer and more concentrated on feed intake. Therefore the treated net of pen protected the animals to a considerable extent against nuisance insects, whereas the untreated net did not serve as an effective barrier. It is assumed the treated net killed most of the muscids trying to enter that particular pen reducing the fly density of the surrounding area. The use of an untreated net in pen showed no benefits as the treated did. The high catches in this pen associated with the high number of counted nuisance insects and defensive movements performed by the stabled animals indicate that the untreated net seemed to retain the insects which entered the pen. In our study from an experimental group a total of 40 animals examined all of them became negative for the parasite and from a control group a total of 15 animals examined two of the animals became parasite positive at monitoring cycle 2 and 4 respectivelly. The Mean PCV value was comparable at $1^{\text {st }}$ monitoring cycle (base line data).However increased at experimental group and decreased at control group starting from $2^{\text {nd }}-5^{\text {th }}$ monitoring cycle as shown in table 4. This research has similar finding with the research made in Kenya (Bauer et al., 2006; (Gouteux and Jarry, 1998). The average milk production was increased at $1^{\text {st }}$ and $2^{\text {nd }}$ monitoring cycle from 2.087 to 2.386 and decreased at $3^{\text {rd }}$ monitoring cycle due to inadequate feed provided by farmers as shown in table 4. This finding has similar result with Studies that have attempted to estimate the outcome on milk yields by controlling nuisance caused by stable flies (Mullens et al., 2006). Protected cattle have shown potential increase of milk yields up to $1.0 \mathrm{~L}$ per day per cow (Morgan and Bailie, 1980).The above finding confirmed that the use of insecticide impregnated net increases production and productivity of the animal which can improve the economy of the farmers, and country at large.

\section{CONCLUSION AND RECOMMENDATION}

Tsetse flies and other biting flies result reduced production and productivity to live stock. In Ethiopia many tsetse fly control activity has under taken under the project southern tsetse and trypanosomiasis eradication project for more a decade ago. However these activities remain under extensive rearing of animals. Now a day due to shortage of grazing land the rearing system was shifted to zero grazing system. In this regard insecticide impregnated net was fenced around selected farmers so as to protect the flies having contact with the animal. During the study entomological, parasitological, and defensive movements as well as weight gain study was made on animals from 30 selected farmers in order to measure productivity. This study will help the farmers as well as country in getting planned revenue from the livestock sector. Based on the above finding the following recommendations were drawn. The study has to occur in different geographic area. Seasonal study should be considered. Feed should be provided to the farmer with a cost sharing in order to support the poor community.

\section{REFERENCES}

[1] (Glossinaspp.) in the pastoral zone of Samorogouan, Burkina Faso. Trop Med 2007).Springer, pp325-335.

[2] ABEBE G., JOBRE Y., 1996. Trypanosomiasis: a threat to cattleproduction in Ethiopia. Revue Méd.vét., 147: 897-902.

[3] Abenga, J.N. I.A. Lawal. 2005. Implicating roles of animal reservoir hosts in the resurgence of Gambian trypanosomiasis (Sleeping Sickness). Afr. J. Biotechnol. 4: 134-137. application of deltamethrin pour on to cattle in a campaign against tsetse flies

[4] Awoke, K., 2000.Study of Trypanosomosis and its Vectors in Humbo and MerabWoredas, Ethiopian Veterinary Association J., 4: 61-67.

[5] Bauer B, Amsler-Delafosse S, Clausen PH, Kabore I, Petrich-Bauer J (1995) Successful

[6] Bauer B, Gitau D, Oloo FP, Karanja SM (2006) Evaluation of preliminary title toprotectzero-grazed dairy cattle with insecticide-treated mosquito screenting in westernKenya. Trop Anim Health Prod 38: 29-34.

[7] Bauer B, Holzgrefe B, Mahama CI, Baumann MP, Mehlitz D, et al. (2011) Managingtsetse transmitted trypanosomosis by insecticide treated screens-an affordable andsustainable method for resource poor pig farmers in Ghana. 
[8] Bauer B, Kabore I, Liebisch A, Meyer F, Petrich-Bauer J (1992) Simultaneous control ofticks and tsetse flies in Satiri, Burkina Faso, by the use of flumethrin pour-on for cattle.Trop Med Parasitol 43: 41-46.

[9] Bouyer, J., L. Guerrini, J. Cesar, S. De la Rocque, D. Cuisance. 2005. A phyto-sociological analysis of the distribution of riverine tsetse flies in Burkina Faso.Med.Vet.Entomol.19:372-378.

[10] Conway-Klaassen, J.M., J.M. Wyrick-Glatzel, N. Neyrinck, P.A. Belair. 2002. African sleeping sickness In a young American tourist. Lab. Med. 33: 783-788.

[11] DAGNACHEW Z., SHAFO K., 1981. An investigation of Dourine inArsi administrative region.Ethiop.vet Bull., 4: 3-9. Experiece in the southern rift valley. In: Area wide control of insect pests from

[12] Goodings, R.H, E.S. Krafsur. 2005. Tsetse Genetics: Contributions to biology, systematic and control of tsetse flies. Annu.Rev.Entomol.50:101-123.

[13] $\mathrm{Hu}, \mathrm{C} ., \mathrm{S}$. Askoy. 2006. Innate immune responses regulate trypanosome parasite infection of the tsetse fly Glossinamorsitansmorsitans. Mol. Microbiol. 60:1194-1204.

[14] Jelinek, J., Z. Bisoffi., L. Bonazzi., P. Van Theil., U. Bronne. 2002. Cluster of African Trypanosomiasis travellers to Tanzanian national parks. Emerg.Infect.Dis. 8:634-635.

[15] K, and Feldemann U (2007). Area wide control of tsetse and trypanosomiasis: Ethiopian

[16] LANGRIDGE W.P., 1976. A tsetse and trypanosomiasis survey ofEthiopia. London, UK, British Ministry of Overseas Development,p. 1-97.

[17] Leak, S.G.A. 1999. Tsetse Biology and Ecology: Their Role in the Epidemiology and Control of Trypanosomiasis. 1st Edn. ILRI, Wallingford, ISBN.pp: 568.

[18] Leak, S.G.A., D. Ejigu, M.J.B. Vreysen. 2008. Collection of Entomological Baseline Data for Tsetse AreaWide Integrated Pest Management Programmes. 1st Edn.Food and Agriculture Organization of the United Nations, Rome, ISBN.pp: 205.

[19] Machado A .1954. Révisionsystématique de glossines du groupepalpalis(Diptera).Publicações Cultures da Companhia de Diamantes de Angola.22. Pp.189.

[20] MURRAY M., MURRAY P.K., MCINTYRE W.I.M., 1977. An improvedParasitological technique for the diagnosis of African trypanosomiasis.Trans. R.Soc. trop.Med.Hyg.,71: 325-326.

[21] Oluwafemi, R.A. 2009. The impact of African animal trypanosomiasis and Tsetse fly on the livelihood and well-being of cattle and their owners in the BICOT study area of Nigeria.Intern.J.Vet. Med. PAAT.2008.Program against AfricaParasitol46:183-189.

[22] researchto field implementation (eds M.J.B. Vreysen, A.S. Robinson, J. Hendrichs,

[23] Sabbah, P. C.Brosset, P. Imbert, G. Bonardel., P.Jeandel.1997. Human African trypanosomiasis: MRI. Neuroradiology.39: 708-710 n Trypanosomiases, Food Agricultural Organizations of the United Nations, Rome.31:pp2.

[24] TAKELE A., ABEBE G., 1988. A survey of trypanosomiasis in GamuGofa region (Ethiopia) Revue Elev. Méd.vét. Pays trop., 41: 271-276.

Citation: Firew Lejebo, et.al, "The Effect of Delthamethrin Treated Net on Tsetse and other Insects in Shara Kebeles, Gamo Gofa Zone, Snnprs "International Journal of Research Studies In Biosciences (IJRSB), Vol. 7, no. 9, pp. 27-36, 2019. http://Dx.Doi.org/10.20431/2349-0365.0709003

Copyright: (C) 2019 Authors. This is an open-access article distributed under the terms of the Creative Commons Attribution License, which permits unrestricted use, distribution, and reproduction in any medium, provided the original author and source are credited. 